\title{
Inference generation and text comprehension in bilingual children: A case study
}

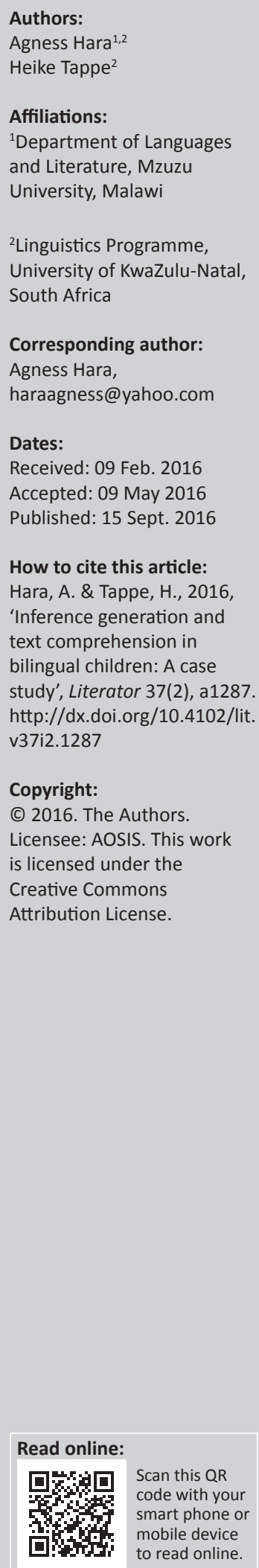

The current study explores inference-making processes in 10-12-year-old bilingual Malawian children who either listened to stories in their primary language, or L1 (Chichewa), as compared to their secondary language (L2) (English), or viewed cartoon films containing no verbal content. The 127 children who participated in the study were divided into six groups characterised by different conditions of stimulus presentation - stimuli varied with respect to their modality (non-verbal film versus pre-recorded stories) or the language of stimulus presentation (English or Chichewa). The results indicate that the pre-recorded audio recordings seem to have supported inference-making more than the corresponding wordless films. This finding illustrates the significance of linguistically presented content. The linguistically presented content elicited even more inferences when it was presented in the children's L1 (Chichewa) rather than in their medium of academic instruction (English). However, the results also indicate that the children from the private school (with English as a medium of instruction) drew more inferences than the children from the public school (where Chichewa is the medium of instruction). Furthermore, the results reveal that while the children were able to use knowledge transfer from a variety of knowledge bases to draw inferences, the inferencing process was impeded when the story content deviated too much from their own experiences. Lastly we found indications of variations in inferencing patterns that seemed to correlate to the language in which the stimulus material was presented and responded to.

Die maak van afleidings en teksbegrip by tweetalige kinders: 'n Gevallestudie. Hierdie studie ondersoek die prosesse waarmee 10-12 jarige tweetalig Malawiese kinders afleidings maak, nadat hulle na stories geluister het in hulle eerste taal (L1) (Chichewa) in vergelyking met stories in hulle sekondêre taal (L2) (Engels) of in strokiesfilms sonder enige verbale inhoud. Die 127 kinders wat aan die studie deelgeneem het, is in ses groepe verdeel volgens die verskillende metodes waarop die stimuli aangebied is. Stimuli het gevarieer ten opsigte van hulle modaliteit (nie-verbale film versus voorafopnames van stories) of die taal waarin die stimulus aangebied is (Engels of Chichewa). Die bevindings dui aan dat die vooraf-gemaakte klankopnames die maak van afleidings ondersteun as die woordelose films. Dit illustreer die belangrikheid van inhoud wat linguisties aangebied word. Die inhoud wat linguisties aangebied is, het selfs meer afleidings ontlok wanneer dit in die kinders se L1 (Chichewa) eerder as in hulle medium van akademiese instruksie (Engels) aangebied is. Die resultate dui egter ook aan dat die kinders van 'n privaatskool (waar Engels die medium van onderrig is) meer afleidings gemaak het as die kinders van 'n staatskool (waar Chichewa die onderrigmedium is). Verder het die bevindings aan die lig gebring dat, hoewel die kinders kennis uit verskeie kennisbasisse kon gebruik om afleidings te maak, die afleidingsproses verswak indien die storie-inhoud te veel van hulle eie ervarings afgewyk het. Laastens het ons bevind dat daar variasies in die afleidingspatrone is wat korreleer met die taal van die stimulusmateriaal en die respons.

\section{Introduction}

In order to understand text, it is essential that comprehenders draw inferences, because generally a text can only provide a certain amount of essential information, which the recipients are required to expand with inferences. Inferences that serve to fill gaps identified in a text are generated through the use of different types of knowledge bases (Keenan, Baillet \& Brown 1984; Kintsch \& Van Dijk 1978; Van Dijk \& Kintsch 1983). Elaborative inferences embellish and amplify written or aural text as well as visual stimuli. These inferences do not help a reader and/or listener achieve comprehension but rather lead to the establishment of a rich situation model. 
There is an enormous number of inferences that comprehenders make; below we provide an overview of different types of inferences with the aim of positioning the subject of our current investigation within the research field.

\section{Different types of inferences}

There is hardly any consensus among researchers in psycholinguistics and discourse processing on the different types of inferences that readers, listeners or viewers make (Graesser, Singer \& Trabasso 1994:374). Table 1 lists the most frequently cited distinctions between different types of inferences.

Graesser et al. (1994:371-372) as well as Pressley and Afflerbach (1995:46-48) compile a comprehensive, rather than exhaustive, account of different types of inferences. The categories that Graesser et al. (1994:371-372) recognise include text-connecting versus knowledge-based inferences on the one hand as well as local versus global inferences on the other hand. The general distinction between text-connecting and knowledge-based inferences is commonly accepted (e.g. Cain \& Oakhill 1999). According to Cain and Oakhill (1999:490), text-connecting inferences involve the integration of textual information and are hence necessary to establish cohesion between sentences. Authors such as Barnes, Dennis and Haefele-Kalvaitis (1996:217-219), Calvo (2004:54) and Bowyer-Crane and Snowling (2005:19-21) adopt the more current terms of coherence versus elaborative inferences to differentiate between text-connecting and knowledge-based inferences, respectively, while Cromley and Azevedo (2007:312) develop yet an alternative set of terminology. They employ the terms text-totext inferences and background-to-text inferences, which are equivalent to the coherence/text-connecting inferences and elaborative/gap-filling inferences, respectively.

Text-connecting inferences are needed to integrate single sentences into one cohesive textbase. Thus, they bridge gaps between different phrases and sentences on a linguistic level. A good example for a text-connecting inference is provided by Cromley and Azevedo (2007:312), who add anaphoric inferences as a sub-category of coherence and/or text-connecting and/or text-to-text inferences. Anaphoric inferences are needed to establish co-reference links among full phrases (Noun Phrases, Verb Phrases, Adjective Phrases), pro-forms and referents.

TABLE 1: Distinctions between different types of inferences.

\begin{tabular}{|c|c|c|}
\hline Authors & Identifying distinctions & between types of inferences \\
\hline McKoon and Ratcliff 1992 & Automatic & Strategic \\
\hline Graesser et al. 1994 & On-line & Off-line \\
\hline Graesser et al. 1994 & Text-connecting & Knowledge-based \\
\hline Graesser et al. 1994 & Local & Global \\
\hline $\begin{array}{l}\text { Barnes et al. 1996; } \\
\text { Calvo } 2004\end{array}$ & Coherence & Elaborative \\
\hline Cain and Oakhill 1998 & Text-connecting & Gap-filling \\
\hline $\begin{array}{l}\text { Bowyer-Crane and } \\
\text { Snowling } 2005\end{array}$ & Coherence & Elaborative/knowledge-based \\
\hline Cromley and Azevedo 2007 & Anaphoric text-to-text & Background-to-text \\
\hline
\end{tabular}

Knowledge-based inferences embellish story content and amplify a story's context. They provide a fuller representation of an event, but they are not central to textual cohesion (Barnes et al. 1996:219). Because these inferences are not necessary to achieve comprehension, they are normally influenced by the accessibility of knowledge. As a specific type of knowledge-based inferences, Cain and Oakhill recognise gap-filling inferences, which make use of information from outside the text (that is, from the reader's existing background knowledge). Knowledge-based inferences generally rely on the activation of a 'mediating idea' from the reader's world knowledge, without which a text may be experienced as disjointed. Graesser, Bertus and Magliano (1995:296) maintain that for knowledge-based inferences to be constructed an interaction between the textbase and long-term memory needs to be activated. As a consequence a subset of long-term memory information may be encoded as inferences in order to create a successful meaning representation of a text. The meaning representation of a text hence comprises both a textbase model and a referential situation model (Kintsch 1988; Van Dijk \& Kintsch 1983).

In terms of the distinction between local and global inferences, Graesser et al. (1994:371) describe the former as those inferences that are essential to the creation of a coherent representation at the local level - that is, for establishing coherence between individual sentences and paragraphs while global inferences establish an overall coherence across the entire text. For instance, at a local level, the reader or listener should be able to identify referents of pronouns, whereas at the global level, the reader should be able to identify the setting of the story, the complication and the resolution.

Other categories of inferences that Graesser et al. (1994:371) present include on-line versus off-line inferences. According to Graesser et al., some inferences are generated during the course of comprehension (on-line), whereas others are only generated during retrieval tasks - that is, after the actual stimulus reception process.

In sum, we can now categorise knowledge-based or elaborative inferences as global, off-line, background-to-text inferences that operate over the general knowledge base of the comprehender and hence use long-term memory representations.

\section{Constructionist versus minimalist views}

In addition to the debate on different categories of inferences, researchers also entertain either a 'minimalist' (e.g. McKoon \& Ratcliff 1992) or a 'constructionist' (e.g. Graesser et al. 1994; Kintsch 1988, 1998, 2004) view of the general character of the inferencing process.

The minimalist view holds 'that there is only a minimal automatic processing of inferences' during comprehension. 
McKoon and Ratcliff (1992:440) maintain that '[...] readers do not automatically construct inferences to fully represent the situation described by the text'. According to the minimalist theory, '[i]nferences that are not required to establish local coherence (i.e. knowledge-based or elaborative inferences) are encoded only to the extent that they are supported by readily available world knowledge' (Long et al. 1996:192). Long et al.'s study indicates that it may be a privilege of advanced readers to be able to carry out elaborate inferences: 'Our data suggest that high-ability readers encode knowledgebased inferences that low-ability readers fail to encode [...] only high-ability readers encode topic-related inferences' (1996:210). This finding may mean that additional knowledge bases that are necessary for elaborative inferencing are only accessed when the comprehender does not experience high cognitive load because of other cognitive processes happening simultaneously; in the case of a less advanced reader, the reading process itself may require all available cognitive resources.

In contrast, the constructionist theory maintains that a comprehender may be engaged in a constant 'search after meaning' in order to build a situation model of a text or a visual stimulus that is coherent both at a local and at a global level. In this way, the comprehender will draw all the inferences needed to explain why things are mentioned in the text - or appear in a film - in order to achieve local and global coherence. Kintsch $(1988,1998,2004)$ developed the construction-integration model (CIM) in order to recognise the role that background knowledge plays in inferencing. This model is relevant to the current study because it identifies different types of knowledge and their role in inferencing and overall comprehension processes.

\section{The construction-integration model}

The CIM includes different levels of mental representation to integrate the propositions and/or ideas that make up the elements of a text representation. The CIM assumes that comprehenders construct a coherent mental representation of the text they are reading or listening to, that is, the situation model. In order to do so, inferences are needed. In the current article our emphasis is on the situation model, which is recognised by most researchers and supported by a plethora of empirical evidence (e.g. Graesser, León \& Otero 2002). Other levels of mental representation, such as the surfacelevel memory, the textbase, the thematic point, the agent perspective, genre and pragmatic context, are discussed by other researchers (see for example Graesser, Olde \& Klettke 2002) and will be referred to if necessary.

\section{The situation model}

The situation model is a type of mental model according to, for example, Johnson-Laird (1983). The term 'mental model' is often used to describe the outcome of comprehension or learning processes in educational psychology (Johnson-Laird 1983:123). Explicit and inferred information about the spatial setting, the style and procedure of actions, the properties of objects and characteristics of agents is part of the situation model and is used to both elaborate and embellish a plot.
The significance of the situation model lies with the fact that information is retained in memory for a certain period of time. Situation models are considered as providing 'deeper' levels of both representation and comprehension than other text-related representations (Graesser, Olde \& Klettke 2002:236). First, situation models that provide elaborate textual representations correspond to a 'deeper understanding of the text [...] and include knowledge-based inferences, that is, those that integrate text and general knowledge' (Barnes et al. 1996:217). Second, its integration with the general knowledge base of the comprehender allows the situation model to be preserved in the comprehender's memory for several days, months or even years. In stark contrast to this, the surface-level memory and the representation of the textbase last for less than a minute and an hour, respectively.

According to Rai et al. (2011:189), inferential processes require working memory, however, as the reader, listener, or viewer needs to hold incoming propositions in working memory while retrieving relevant world knowledge from long-term memory into working memory. During this process comprehenders need to use their world knowledge to fill in any propositions that are missing from the incoming stream of information for the situation model to make sense (Rai et al. 2011:189).

Rai et al. emphasise that second language listeners frequently need to use considerable processing resources in order to decode the surface and textbase levels. This means that there are fewer working memory resources left for second language listeners to draw inferences from the situation model level. This constraint makes second language listening even more challenging than first language listening (Horiba 1996; Kembo 2001; Walter 2004). As a result of such working memory limitations, inferences drawn from a second language comprehension task may be fewer than inferences drawn from a first language comprehension task. This may impede second language listeners in comprehension tasks, because the smaller number of inferences may prevent them from constructing a coherent mental representation of a stimulus. According to Tibus (2008:18), '[t]o form a coherent mental representation of the text, the reader needs to generate a situation model. To transform the textbase into a situation model, inferences are again necessary'.

The construction of a coherent situation model may hence be hindered not only by the processing of current knowledge but also by a lack of pre-existing knowledge. Such knowledge is often stored in the form of schemas. In the section that follows, we explain the role that schemas play in comprehension.

\section{The role played by schemas in comprehension}

Research in psychology and cognitive science demonstrates that our past experiences and our background knowledge 
play a crucial role in comprehension, some of which may be stored in the form of schemas ${ }^{1}$ (or schemata). In his seminal work that lay the groundwork for modern schema theory, Bartlett (1932:201) defines a schema as 'an active organization of past reactions, or of past experiences, which must always be supposed to be operating in any well-adapted organic response'.

Kintsch and Greene's (1978) study asked US college students to read and subsequently summarise two vastly different stories, a Grimm fairy tale (experiment I) and a Native American (Apache) story (experiment II). The results showed that the US participants found it more challenging to recall the Native American story, as it seemed less familiar and less integrated in their own culture than the Grimm fairy tale. Such results suggest that story schema may be culturespecific.

Similar results, which seem to confirm that story schemas are culture-specific, generally demonstrate a positive relationship between cultural familiarity and reading or listening comprehension (Alptekin 2006; Carrell 1987; Carrell \& Eisterhold 1983; Erten \& Razi 2009; Hara 2015; Jalilifar \& Assi 2008; Johnson 1981; Li \& Lai 2012; Pritchard 1990; Sasaki 2000; Tappe \& Hara 2013). For example, Erten and Razi (2009) investigated whether cultural familiarity influences comprehension of short stories. For this aim the authors 'nativised' the story that they used for reading comprehension. They did this by changing the names of characters, places, streets and buildings from American to Turkish names. Moreover, they also changed some conceptual cues in order to ensure that the story followed a schema that was specific to Turkish storytelling. For instance, in the nativised story the protagonists planned to eat fish rather than steak as in the original story, since the location of the nativised story was a coastal city (Erten \& Razi 2009:65). The two groups of participants who read the nativised story produced higher scores in reading comprehension tests than the other two groups, who read the original story, which indicates that there was better comprehension of the nativised story. Similarly, findings in Sasaki's (2000:85) study indicated that participants who read a text with culturally familiar names performed better in a free recall task than those who read the same text with unfamiliar names.

\section{The present study}

The current study investigates knowledge-based (i.e. elaborative inferences) in 10-12-year-old bilingual Malawian children. Inferencing was investigated not only when the children listened to stories in their primary language, or L1 (Chichewa), as compared to their secondary language, or L2 (English), but also when they viewed wordless cartoon films. The study adopted a question-answering methodology to reveal whether the children used knowledge either from the previous text or from their knowledge base to amplify

\footnotetext{
1. We are aware of the system dynamics theory, but our focus in this study was on the role played by inferences in the construction of a coherent mental representation of a text, hence our analysis of inferences.
}

their situation model with inferred information. In particular, the participants answered why questions (e.g. 'why did the engine of the rocket stop working?') and what questions (e.g. 'what was the bee doing inside the flowers at the beginning of the story?').

\section{Method Participants}

Our participants were learners at two different schools: a private school, Kapita Primary School, and a public school, Mphungu Primary School, which are both located in the Central Region of Malawi in the capital city, Lilongwe. The medium of instruction at Kapita Primary School is English in all grades except when studying a language such as Chichewa as a school subject. In contrast, Chichewa is the medium of instruction from grade 1 to grade 4 at Mphungu Primary School. The language policy in Malawi permits the use of a mother tongue from grades 1 to 4 in public schools, and English becomes the medium of instruction beginning in grade 5 .

The total number of participants was 127 children (64 female, 63 male) aged between 10 and 12 years (44 10-year-olds, 40 11-year-olds and 43 12-year-olds). At the time of the study, 69 of the children were attending the private school (Kapita), while 58 of them were attending the public school (Mphungu).

Most of the participants were from the same urban community, while some of the participants who attended the public school were from rural areas. On average, the participants who attended the private school were from a higher socio-economic background than those who attended the public school.

\section{Language background questionnaire}

Parents who had given consent for their children to participate in the study were provided with a language background questionnaire, in which we asked about the language repertoire of the children, the children's involvement in storytelling, languages used in storytelling, the children's knowledge of oral traditional practices and languages used when engaging in these oral traditional practices (see Table 2). An English version of the questionnaire was distributed to the parents at the private school (Kapita), whereas the parents at the public school (Mphungu) received a Chichewa version. ${ }^{2}$

\section{Material}

The elicitation material used in this study comprised two wordless cartoon films ['The mole and the rocket' (1966) and 'The mole and the radio' (1968), developed for children by the Czech cartoonist Zděnek Miler in $1956^{3}$ ] and two aural

2. The language choice for the parental questionnaires followed school policy: The head teacher at Kapita Primary School informed the first author that English was the head teacher at Kapita Primary School informed the first author that English was the medium of communication with the parents, while the head teacher at Mphungu Primary School confirmed that Chichewa was the medium of communication with the parents.

3. The films were chosen because they have enjoyed great popularity in many countries around the world since their creation. 
TABLE 2: Background information about children attending Kapita and Mphungu primary schools.

\begin{tabular}{|c|c|c|c|c|c|c|}
\hline \multirow[t]{2}{*}{ Background information } & \multicolumn{3}{|c|}{ Kapita } & \multicolumn{3}{|c|}{ Mphungu } \\
\hline & Chichewa & English & $\begin{array}{l}\text { Both English and } \\
\text { Chichewa }\end{array}$ & Chichewa & English & $\begin{array}{l}\text { Both English and } \\
\text { Chichewa }\end{array}$ \\
\hline Language(s) used in storytelling at home & 15 & 9 & 38 & 36 & 2 & 18 \\
\hline Ability to [re]tell stories in languages & 17 & 6 & 43 & 39 & 3 & 15 \\
\hline
\end{tabular}

Source: Hara, A., 2015, 'Text comprehension in multilingual children: Mental representation and narrative text structure', PhD thesis, Department of Linguistics, University of KwaZulu-Natal

stories that captured the events depicted in the cartoon stories, each of which had a Chichewa and an English version.

An English verbal version of each of the cartoon films was constructed by a postgraduate student in Creative Writing. In terms of comparability to the film, the student adopted the measures used by Meringoff (1980) and Salomon (1984). The stories were then edited by two mother tongue speakers of English who were lecturers by profession, one in Linguistics and the other in English Studies. The Chichewa versions of the stories were created by a specialist in Chichewa, who translated the stories. His translations were subsequently edited by two lecturers in African Languages and Linguistics, who were mother tongue speakers of Chichewa. We ensured that the written stories were as equivalent as possible across the two languages by employing an independent translator who back-translated the Chichewa versions into English.

In a final step, the participants' teachers assessed the stories in order to ensure that they were at an appropriate level of grammatical and lexical complexity for the participants.

\section{Procedure}

The participants were divided into six groups. Each group of 20-21 children was assigned a different story condition (condition 1 (a) to condition 5). Conditions varied according to the modality of the stimulus material (film vs. aural stories) and the language of stimulus presentation (English or Chichewa). In all conditions, the first author and the local assistant tested the participants individually in a vacant room at their school. The children were briefed on their rights and signed the informed consent form. They were requested to pay close attention to the stimulus material and were told that we would ask comprehension questions based on the film or aural story. ${ }^{4}$ All sessions were audio-recorded.

\section{Condition 1 (a)}

Each child watched the cartoon film 'The mole and the rocket' (1966) and subsequently answered comprehension questions in English. After a 1-week time lapse, the participants watched the second cartoon film, 'The mole and the radio' (1968). Again they answered comprehension questions in English.

\section{Condition 1 (b)}

Each child watched the cartoon film ('The mole and the rocket') and afterwards answered comprehension questions in Chichewa. The children watched the next cartoon film,
'The mole and the radio' (1968), after a 1-week time lapse and subsequently answered comprehension questions in Chichewa.

\section{Condition 2}

Each child listened to a pre-recorded reading of the story 'The mole and the rocket' in English. After listening to the story, they answered comprehension questions in English. After a 1-week time lapse, the children listened to a prerecorded reading of the second story, 'The mole and the radio', in English. After listening to the story, they answered comprehension questions in English.

\section{Condition 3}

Each child listened to a pre-recorded reading of the story 'The mole and the rocket' in Chichewa. After listening to the story, they answered comprehension questions in Chichewa. After a 1-week time lapse, the children listened to a prerecorded reading of the second story, 'The mole and the radio' in Chichewa. After listening to the story, they answered comprehension questions in Chichewa.

\section{Condition 4}

Each child listened to a pre-recorded reading of the story 'The mole and the rocket' in Chichewa. However, after listening to the story, children answered comprehension questions in English. After a 1-week time lapse, the children listened to a pre-recorded reading of the second story, 'The mole and the radio', in Chichewa. Again they answered comprehension questions in English.

\section{Condition 5}

Each child listened to a pre-recorded reading of the story 'The mole and the rocket' in English. However, after listening to the story, the children answered comprehension questions in Chichewa. After a 1-week time lapse, the children listened to a pre-recorded reading of the second story, "The mole and the radio', in English. Again they answered comprehension questions in Chichewa.

In particular, we asked the children the following six questions to elicit elaborative inferences.

\section{Rocket story questions:}

- Why did the engine of the rocket stop?

- Why did the little mole not dive into the sea to look for the parts of the rocket himself?

- Why did the mole make friends with this sea creature? 
Radio story questions:

- What was the bee doing inside the flowers at the beginning of the story, and what was the bee doing inside the flowers towards the end of the story?

- Why did the radio make strange noises and then completely stop playing?

- Why did the mole wrap the scarf around the radio?

\section{Data analysis}

Each of the participants' answers to the questions were transcribed and thereafter analysed. The following procedure was used in the analysis: All the answers that were based on information that was not explicitly stated in the stories were considered inferences. Such answers were kept for further analysis. In contrast, all the answers that were classified as text-based were put aside, as our study only focused on inferences. Thereafter, the inferences were further analysed in order to find the total number of inferences that were drawn in English and Chichewa by both groups of participants from each of the two stories. These inferences were arranged in accordance with the stated conditions that participants were assigned to. Further analysis was conducted in order to determine the total number of inferences drawn by each group of participants (Kapita vs. Mphungu) from each of the two stories. Further analysis enabled us to put together inferences that depicted the participants' preexisting knowledge bases and those that depicted the children's use of knowledge transfer from other subjects.

Inferences in the participants' answers were initially identified by the first author, and they were subsequently verified by the second author. The answers that were in Chichewa were verified by the first author's colleague, a specialist in African Linguistics. For all the inferences that were identified, inter-coder agreement was high $(97 \%$ and $98 \%$, respectively). Cases of disagreements between coders were discussed and resolved.

\section{Ethical considerations}

Ethical clearance for the current study was granted by the University of KwaZulu-Natal's Ethics Review Committee (no. HSS/0246/012D). We obtained formal written consent from the school principals, teachers, parents and children prior to the study.

\section{Results}

In order to present our findings, we first compare the total number of inferences that participants drew when they were answering comprehension questions in their L1 with those they drew when they used their L2. We compare these results with information that shows that participants from Kapita Primary School generated more inferences than participants from Mphungu Primary School. Subsequently we contrast the total number of inferences drawn when the mode of presentation was aural (pre-recorded story) with those drawn when the mode of presentation was visual (film). Thereafter, we compare the total number of inferences from 'The mole and the rocket' (hereafter 'the rocket story') with those drawn from 'The mole and the radio' (hereafter 'the radio story'). We also present results reflecting that participants were using knowledge transfer from a variety of school subjects when answering the comprehension questions.

\section{Inferences in L1 and L2}

The participants drew a total of 81 inferences from the radio story and 49 inferences from the rocket story when answering comprehension questions in English. However, they managed to draw a total of 97 inferences from the radio story and 78 inferences from the rocket story when answering comprehension questions in Chichewa (see Tables 3 and 4).

There were a number of inferences that were common regardless of the language used, for example, the engine of the rocket stopped working because it did not have enough oil or it stopped working because the mole was failing to control it. However, there were also inferences that seemed to be language-specific, for example when responding to the question, 'what is the bee doing in the flower?', some of the children included answers such as 'the bee is pollinating the flowers', 'the bee is collecting nectar' or 'the bee is eating the nutrients found in flowers' when the language of verbalisation was English. The children did not include such answers when answering the same question in Chichewa.

The data in Tables 3 and 4 also reveal that the mismatch between the stimulus language and the response language (conditions 4 and 5) had an impact on the inferences drawn. For instance, more inferences were drawn in condition 5 from both the radio story (19 and 19) and the rocket story (18 and 10) (i.e. when the children had listened to the story in English and answered the questions in Chichewa). In contrast, only a few inferences were drawn in condition 4 , that is when the children had listened to the story in Chichewa and answered the questions in English ( 3 from the radio story and 0 and 1 from the rocket story).

\section{Inferences in relation to the school type}

The results in this section suggest an interaction between the language of instruction and the capability to react to inference elicitation questions in this language. While both groups of children were L1 Chichewa speakers who had a significant amount of exposure to Chichewa at home according to the parental questionnaire (see Table 2), our results show that the children from Mphungu Primary School drew more inferences than the children from Kapita Primary School when answering comprehension questions in Chichewa; this holds especially for condition 1 (b) (for both stories) and for condition 5 (for the rocket story only).

Conversely, when comprehension questions were answered in English the children who attended Kapita Primary School (i.e. private school) drew more inferences than those 
TABLE 3: Total number of inferences drawn in English and Chichewa by both groups of participants from the radio story.

\begin{tabular}{|c|c|c|c|c|c|}
\hline Question number & Story title & Condition (English) & Number of inferences (English) & Condition (Chichewa) & Number of inferences (Chichewa) \\
\hline \multirow[t]{3}{*}{ Question 1} & 'The mole and the radio' & 1 (a) & 11 & 1 (b) & 10 \\
\hline & 'The mole and the radio' & 2 & 17 & 3 & 14 \\
\hline & 'The mole and the radio' & 4 & 14 & 5 & 19 \\
\hline \multirow[t]{3}{*}{ Question 2} & 'The mole and the radio' & 1 (a) & 9 & 1 (b) & 6 \\
\hline & 'The mole and the radio' & 2 & 5 & 3 & 7 \\
\hline & 'The mole and the radio' & 4 & 6 & 5 & 6 \\
\hline & 'The mole and the radio' & 2 & 6 & 3 & 11 \\
\hline & 'The mole and the radio' & 4 & 3 & 5 & 19 \\
\hline Total & - & - & 81 & - & 97 \\
\hline
\end{tabular}

Source: Hara, A., 2015, 'Text comprehension in multilingual children: Mental representation and narrative text structure', PhD thesis, Department of Linguistics, University of KwaZulu-Natal

TABLE 4: Total number of inferences drawn in English and Chichewa by both groups of participants from the rocket story.

\begin{tabular}{|c|c|c|c|c|c|}
\hline Question number & Story title & Condition (English) & Number of inferences (English) & Condition (Chichewa) & Number of inferences (Chichewa) \\
\hline \multirow[t]{3}{*}{ Question 1} & 'The mole and the rocket' & 1 (a) & 11 & 1 (b) & 9 \\
\hline & 'The mole and the rocket' & 2 & 12 & 3 & 12 \\
\hline & 'The mole and the rocket' & 4 & 10 & 5 & 11 \\
\hline \multirow[t]{3}{*}{ Question 2} & 'The mole and the rocket' & 1 (a) & 6 & 1 (b) & 8 \\
\hline & 'The mole and the rocket' & 2 & 7 & 3 & 6 \\
\hline & 'The mole and the rocket' & 4 & 0 & 5 & 18 \\
\hline \multirow[t]{3}{*}{ Question 3} & 'The mole and the rocket' & 1 (a) & 2 & 1 (b) & 1 \\
\hline & 'The mole and the rocket' & 2 & 0 & 3 & 3 \\
\hline & 'The mole and the rocket' & 4 & 1 & 5 & 10 \\
\hline Total & - & - & 49 & - & 78 \\
\hline
\end{tabular}

Source: Hara, A., 2015, 'Text comprehension in multilingual children: Mental representation and narrative text structure', PhD thesis, Department of Linguistics, University of KwaZulu-Natal

TABLE 5: A comparison of the total number of inferences by each group.

\begin{tabular}{|c|c|c|c|c|c|c|c|c|}
\hline \multirow[t]{2}{*}{ Condition } & \multicolumn{2}{|c|}{$\begin{array}{l}\text { Results from the rocket story } \\
\text { when using English (L2) }\end{array}$} & \multicolumn{2}{|c|}{$\begin{array}{l}\text { Results from the rocket story when } \\
\text { using Chichewa (L1) }\end{array}$} & \multicolumn{2}{|c|}{$\begin{array}{l}\text { Results from the radio story when } \\
\text { using Chichewa (L1) }\end{array}$} & \multicolumn{2}{|c|}{$\begin{array}{l}\text { Results from the radio story wher } \\
\text { using English (L2) }\end{array}$} \\
\hline & Kapita & Mphungu & Kapita & Mphungu & Kapita & Mphungu & Kapita & Mphungu \\
\hline Condition 1 (a) & 7 & 4 & 4 & 5 & 3 & 7 & 7 & 4 \\
\hline Condition 4 & 7 & 3 & 5 & 6 & 10 & 9 & 8 & 6 \\
\hline
\end{tabular}

Source: Hara, A., 2015, 'Text comprehension in multilingual children: Mental representation and narrative text structure', PhD thesis, Department of Linguistics, University of KwaZulu-Natal L1, first language; L2, second language

who attended Mphungu Primary School (i.e. public school) (see Table 5) - this observation holds for all conditions.

The quantitative results presented in Table 5 tie in with observations on the nature of the inferences that the children were able to draw.

Where answers were required in Chichewa, those children who attended the public Mphungu Primary School provided much greater detail in their answers than their peers from the private Kapita Primary School; compare example sentences 1 and 2, which were produced by participants attending the public Mphungu Primary School:

'Inakwera mmwamba kwambiri ndi mphamou ndiye injini inakhala ngati yatopa nkusiya kugwira ntchito.' [It went very far in the sky; as a result the engine got tired and it stopped working.] (Participant from Mphungu Primary School, Female, Age 11)

'Inali itayenda kwambiri ndiye itayenda kwambiri muja utsi unayamba tsopano, mphamou zinayamba kutha, zitatha muja, utsi womaliza unatuluka, ndiye utatuluka, basi zinapezeka zakuti loketi ija yagwera mmadzi.' [It had covered a lot of distance; as a result it lost power and fumes started coming out, and thereafter the last fumes came out and the rocket ended up crashing in the water.] (Participant from Mphungu Primary School, Male, Age 12)
In comparison the children who attended the private Kapita Primary School struggled with verbalising their inferences in great detail in Chichewa. Their Chichewa answers typically consisted of short phrases and lacked specific names for referents as exemplified in examples 3 and 4:

'Chifukwa sanasiyemo mafuta ambiri.' [Because the fuel was not enough.] (Participant from Kapita Primary School, Male, Age 11)

'Inalibe mafuta ambiri.' [It didn't have enough fuel.] (Participant from Kapita Primary School, Male, Age 11)

The opposite holds for inferences that were verbalised in English. Here, the children who attended the private Kapita Primary School provided more detailed verbalisations of inferences than their peers from the public Mphungu Primary School. The level of detail of the English verbalisations from children attending the private Kapita Primary School is illustrated in examples 5 and 6:

'It stopped because, the engine of the rocket stopped because there was no [sic] any oil or things to put into the engine.' (Participant from Kapita Primary School, Female, Age 10)

'It crashed because the mole didn't know how to control it and where to go.' (Participant from Kapita Primary School, Female, Age 12) 
In comparison the children who attended the public Mphungu Primary School typically provided short answers that lacked specific names for referents; this is represented in examples 7 and 8:

'I think it needed fuel.' (Participant from Mphungu Primary School, Female, Age 12)

'It was overspeeding.' (Participant from Mphungu Primary School, Female, Age 11)

Our results thus indicate that the dominant language for the two sets of children may be determined by the type of school they are attending: Chichewa seems to have been the dominant language for the children attending the public Mphungu Primary School, whereas English seems to have been the dominant language for the children who were attending the private Kapita Primary School. The language background questionnaire supports this finding, as the children who attended Kapita Primary School seemed to have much less exposure to Chichewa at home than their peers from Mphungu Primary School (see Table 2). The language of communication for the Kapita Primary School children at home and at school was mainly English, whereas for the Mphungu Primary School children, it was mainly Chichewa.

\section{Inferences in relation to the modality of the stimulus}

The results in this study show that participants drew more inferences when the mode of presentation was aural rather than visual (film) (see Table 6).

The total number of inferences for conditions 1 (a) and 1 (b) - where the stimulus was the non-verbal film - were 49 and 39 , respectively, which was generally lower than the total number of inferences obtained when the mode of presentation was aural (compare the numbers in Table 6 below).

The general pattern revealed in this table is that the number of inferences drawn from the visual mode (i.e. 88) was lower than those drawn from the aural mode of presentation (i.e. 100 and 117). The results in this table also indicate that the total number of inferences drawn from the rocket story in each condition (19, $18,19,21,11,39)$ was lower than the total number of inferences drawn from the radio story $(30,21,28,32,23,44)$. This may have been so because the rocket story was generally rather difficult for the Malawian children (see the inferences in relation to the familiarity of the story section below).

\section{Inferences in relation to the familiarity of the story}

The results indicate that the participants drew more inferences when answering comprehension questions from the radio story than the rocket story. While the children verbalised only 49 inferences in English and 78 inferences in Chichewa about the rocket story, they verbalised 81 inferences in English and 97 inferences in Chichewa about the radio story (see Table 7).

These results seem to reflect the fact that the rocket story is centred on the idea of travelling by rocket and crashing with the rocket on the seashore. In order to be able to return home, the mole then has to reassemble the rocket with the help of sea creatures. Overall the story seemed to appear alien to the children, who grew up in a landlocked country. We found in an earlier study that they struggled to retell this story (Hara 2015: 215-216). In contrast the radio story, in which the mole alienates all his friends by constantly playing his new radio too loudly, seemed to be much more familiar to the children and hence easier to retell (Hara 2015: 215-216). We generally found that inference-making was facilitated when the children were able to integrate the story content with preexisting knowledge bases.

\section{Inferences in relation to the children's pre-existing knowledge bases}

The results revealed that the participants were able to use a variety of knowledge bases in their inference-making processes to understand information that was not made explicit in the stimulus material (see Tables 8 and 9).

TABLE 6: Total number of inferences drawn from the two modes of presentation (aural and visual).

\begin{tabular}{|c|c|c|c|c|c|c|}
\hline Question number & Story title & Condition (English) & $\begin{array}{c}\text { Number of inferences } \\
\text { (English) }\end{array}$ & Condition (Chichewa) & $\begin{array}{c}\text { Number of inferences } \\
\text { (Chichewa) }\end{array}$ & Total \\
\hline $1,2,3$ & 'The mole and the radio' & 1 (a) & 30 & 1 (b) & 21 & 51 \\
\hline $1,2,3$ & 'The mole and the rocket' & 1 (a) & 19 & $1(b)$ & 18 & 37 \\
\hline Total & - & - & 49 & - & 39 & 88 \\
\hline $1,2,3$ & 'The mole and the radio' & 2 & 28 & 3 & 32 & 60 \\
\hline $1,2,3$ & 'The mole and the rocket' & 2 & 19 & 3 & 21 & 40 \\
\hline Total & - & - & 47 & - & 53 & 100 \\
\hline $1,2,3$ & 'The mole and the radio' & 4 & 23 & 5 & 44 & 67 \\
\hline $1,2,3$ & 'The mole and the rocket' & 4 & 11 & 5 & 39 & 50 \\
\hline Total & - & - & 34 & - & 83 & 117 \\
\hline
\end{tabular}

Source: Hara, A., 2015., 'Text comprehension in multilingual children: Mental representation and narrative text structure', PhD thesis, Department of Linguistics, University of KwaZulu-Natal

TABLE 7: A comparison of the number of inferences drawn from the two stories

\begin{tabular}{lccc}
\hline Story title & Number of inferences (English) & Number of inferences (Chichewa) & Total number of inferences \\
\hline 'The mole and the radio' & 81 & 97 & 178 \\
'The mole and the rocket' & 49 & 78 & 127 \\
\hline Total & $\mathbf{1 3 0}$ & $\mathbf{1 7 5}$ & $\mathbf{3 0 5}$ \\
\hline
\end{tabular}

Source: Hara, A., 2015, 'Text comprehension in multilingual children: Mental representation and narrative text structure', PhD thesis, Department of Linguistics, University of KwaZulu-Natal 
TABLE 8: Inferences in relation to the children's pre-existing knowledge bases for the radio story.

\begin{tabular}{|c|c|c|c|c|c|}
\hline \multirow[t]{2}{*}{ Condition } & \multicolumn{5}{|c|}{ Elaborative inferences in relation to the question 'what is the bee doing in the flower?' } \\
\hline & $\begin{array}{l}\text { Food: 'Juice', 'food', 'sugar' 'water', } \\
\text { 'honey', 'nectar', 'nutrients' }\end{array}$ & Pollination & $\begin{array}{l}\text { Habitation: 'It is living in the } \\
\text { flower' }\end{array}$ & Other answers & Total \\
\hline Condition 1 (a) & 9 & 1 & 0 & 1 & 11 \\
\hline Condition 2 & 12 & 1 & 2 & 2 & 17 \\
\hline Condition 4 & 8 & 2 & 1 & 3 & 14 \\
\hline Condition 1 (b) & 8 & 0 & 2 & 0 & 10 \\
\hline Condition 3 & 6 & 0 & 2 & 6 & 14 \\
\hline Condition 5 & 14 & 0 & 4 & 1 & 19 \\
\hline
\end{tabular}

Source: Hara, A., 2015, 'Text comprehension in multilingual children: Mental representation and narrative text structure', PhD thesis, Department of Linguistics, University of KwaZulu-Natal

TABLE 9: Use of knowledge transfer from other subjects for 'the rocket story'.

\begin{tabular}{|c|c|c|c|c|c|c|c|}
\hline \multirow[t]{2}{*}{ Condition } & \multicolumn{7}{|c|}{ Comprehension answers from the rocket story arranged according to different themes } \\
\hline & Lack of fuel & $\begin{array}{l}\text { Inability to control } \\
\text { the rocket }\end{array}$ & Low batteries & $\begin{array}{l}\text { Over speeding or } \\
\text { over heating rocket }\end{array}$ & $\begin{array}{l}\text { Intrusion of strong wind } \\
\text { or water into the engine }\end{array}$ & Other answers & Total \\
\hline Condition 1 (a) & 5 & 2 & 2 & 1 & 0 & 1 & 11 \\
\hline Condition 2 & 4 & 2 & 0 & 1 & 2 & 3 & 12 \\
\hline Condition 4 & 5 & 0 & 0 & 1 & 0 & 4 & 10 \\
\hline Condition 1 (b) & 2 & 5 & 0 & 0 & 0 & 2 & 9 \\
\hline Condition 3 & 2 & 4 & 0 & 0 & 1 & 5 & 12 \\
\hline Condition 5 & 1 & 2 & 0 & 2 & 2 & 4 & 11 \\
\hline
\end{tabular}

Source: Hara, A., 2015, 'Text comprehension in multilingual children: Mental representation and narrative text structure', PhD thesis, Department of Linguistics, University of KwaZulu-Natal

With respect to the radio story, the participants were able to embellish their situation model of the story with information from a variety of school subjects, as they stated that a bee featured in the radio story was looking for 'food', 'juice', 'sugary water' in response to the question of what the bee was doing inside a flower. Four participants even used the technical term 'pollination', which confirms that the participants were able to tap into other knowledge sources, for example knowledge acquired in school subjects such as Biology (see Table 8 for an overview).

It is interesting that condition 3 , where both the question and the children's answers were formulated in Chichewa, yielded the highest number of alternative answers ('other answers' e.g. 'the bee was playing inside the flowers', 'the bee was playing with his friends', 'the bee was eating the flowers'). This observation warrants further investigation.

Even though the rocket story was more difficult for the children to draw inferences from and to recall, they still managed to employ their knowledge base and were able to supplement the information that was explicitly provided in the film or audio recording with their own knowledge (see Table 9 for an overview).

In order to comprehend why the rocket had to crash-land, the children drew the following inferences: the rocket had no fuel; the mole was not able to control the rocket; the batteries were low; the rocket was over speeding or overheating; a strong wind or water may have entered the engine. Neither the film nor the audio recording included any explanation for the rocket's engine failure.

\section{Discussion}

The discussion in this section follows the sequence in which we present our findings in the previous section. First, we deliberate the relationship between inference-making and the children's language constellation and relate these findings to the influence of the school type/socio-economic background. Subsequently we consider reasons why the participants drew more inferences from aural stories than visual stories and why there were more inferences from the radio story than the rocket story. In connection with the latter, we reflect on the relationship between cultural familiarity and comprehension skills. Lastly, this section discusses findings pertaining to the participants' use of their knowledge bases in their inference-making processes.

Overall our participants drew more inferences when they answered comprehension questions in their L1 as compared to their L2. This is in line with findings that indicate that second language listeners have fewer working memory resources at their disposal than first language listeners, which makes listening in a second language an even more challenging task than first language listening (Horiba 1996; Kembo 2001; Walter 2004). As inferential processes require working memory (Rai et al. 2011:189), working memory limitations may impede second language comprehension tasks. Such limitations in inference-making in the second language may prevent listeners from building coherent situation models from a text or film.

Our results furthermore indicate important interactions between the children's language constellations and the type of school that they attend, which in turn relates to their socioeconomic background.

Starting with the latter aspect, we found that children who attended the private Kapita Primary School were generally able to draw more inferences than the children who attended the public Mphungu Primary School. This advantage of the children who attended a private school may be related to the fact that the school type corresponds 
to a higher socio-economic background. According to Hecht et al. (2000:99), there is evidence that children from affluent socio-economic status (SES) homes obtain higher scores on 'measures of reading attainment at school entry' than those from lower SES backgrounds. An affluent home is more likely to be a home with a stable family background and less demand on the children to carry out household chores after school (Slatalla 2001:75). Moreover, affluent homes are more likely to be headed by a parent or parents with a higher education, who may be more likely to be able to afford books and other reading materials. Hence such parents may be able to respond to insight into the necessity of narrative skills development by buying reading materials and thus aligning their children's narrative skills development with the narrative skills that are required in the school environment. ${ }^{5}$

Moreover, it is conceivable that the children who attended Kapita Primary School had the luxury of regular exposure to stories in the film medium both at home and at school, while many children attending the under-resourced Mphungu Primary School might not have enjoyed either of these privileges. Linebarger and Piotrowski (2009:61-62) demonstrate, however, that story knowledge and exposure to repeated televised narratives may enhance the development of story schemas, which '[...] contribute to greater narrative involvement that, in turn, contributes to greater efficiency in storing and interpreting narrative content'. ${ }^{6}$ However, the prevalence of the television sets in the affluent homes may explain why, according to the parental questionnaire, a greater percentage of public school children $(56 / 58)$ were exposed to storytelling at home, as compared to $62 / 69$ children attending the private school. ${ }^{7}$

Crucially, our results indicate that participants from Mphungu Primary School drew more inferences than participants from Kapita Primary School when answering comprehension questions in Chichewa, especially in condition 1 (b) (both stories) and condition 5 (i.e. the rocket story only), whereas participants from the private Kapita Primary School drew more inferences when answering comprehension questions in English (i.e. in all the assigned conditions). These results may be related back to the parental questionnaire, which indicated that the majority of children attending Mphungu Primary School (36/58) used Chichewa when narrating stories at home and had the ability to [re]tell stories in Chichewa (see Table 2), whereas only 18 of them $(18 / 58)$ used both English and Chichewa during storytelling at home and an even lower number $(15 / 58)$ had the ability to [re]tell stories in both languages. The children attending Kapita Primary School had a strikingly different language

5. We found that all of the children were exposed to storytelling in the home. However the children who attended Mphungu Primary School were predominantly exposed to storytelling in Chichewa, which indicates that they were exposed rather to oral, traditional storytelling (cf. footnote 7).

6. The proposed correlation between exposure to stories and performance in story recalls and comprehension tasks is further supported by numerous other pieces of research (e.g. Cruz de Quirós et al. 2012; Fiestas \& Peña 2004; Patterson 2002; Scheele, Leseman \& Mayo 2010; Severing \& Verhoeven 2001).

7. Obviously, not all parents from affluent homes engage in storytelling sessions with their children. It is possible for an affluent home to be headed by a parent or parent who do not have time to read stories to their children. background; here the majority of children (38/69) used both English and Chichewa when narrating stories at home, and 43/69 had the ability to use both languages when [re]telling stories (see Table 2). Bartlett (1932) suggests that constant exposure to a certain phenomenon results in a generic cognitive representation of the phenomenon. In an earlier study (Tappe \& Hara 2013) we maintain that the prevalence of storytelling in Chichewa in the homes of our participants may have led to a 'generic cognitive representation' of culture-specific schemata and a generic text representation pattern that we dubbed a 'Southern African Story Grammar'; we argue that these need to be acknowledged in an educational context. ${ }^{8}$ We find it striking that in the current investigation we obtained the highest number of 'alternative' answers when the children were answering in Chichewa to a question that was also posed in Chichewa. We hypothesise that the Chichewa-only condition may have triggered access to different knowledge sources, different hearer models and a different conceptualisation of the task itself in the children. This idea, as well as the role of indigenous storytelling and its relation to inference-making, needs to be further explored.

A further striking result of our investigation is that the participants drew more inferences when the mode of presentation was aural rather than visual (film). The children may have paid more attention to verbal text, a suggestion that is in line with Meringoff's study (1980:247), which also found that children paid great attention to verbal text. Similarly, Beagles-Roos and Gat (1983:135) found that children rely on the words that they hear in their recalls of stories being read to them. The aurally presented story led younger children 'to go beyond the explicit and implicit story content to substantiate their inferences' (Beagles-Roos \& Gat 1983:135). Moreover our participants may have been especially familiar with oral storytelling and may have found responding with comprehension questions to the visual medium rather unfamiliar.

Our results also confirm a positive relationship between cultural familiarity and reading or listening comprehension as indicated by Alptekin (2006), Erten and Razi (2009), Jalilifar and Assi (2008), Johnson (1981) and Li and Lai (2012). We found that our participants drew more inferences from the radio story than from the rocket story. The plot of the radio story is more familiar to Malawian children than travelling in a rocket and being stranded on a beach populated with beach paraphernalia and sea creatures. Most people in Malawi own a radio as opposed to a television set. Moreover, children who live in a landlocked country may be very unfamiliar with beach life. Drawing inferences from a story that was alien, with unfamiliar characters, may well have been a challenge for most of the children in this study.

Finally, our results revealed that the children were to a certain extent able to use knowledge bases like, for instance,

8. This hypothesis is partially based on the fact that there is a paucity of reading materia in Chichewa and we hence assume that the children and their families engaged in the in Chichewa and we hence assume that the children and their families engaged in the
narration of Chichewa folk tales. We found evidence for this assumption in our earlier investigations of the same children (Hara 2015; Tappe \& Hara 2013). 
knowledge learned in a variety of school subjects such as science in their inference-making processes. This is in accordance with the finding that comprehenders make use of a variety of sources, for example knowledge about the language used in the text, general world knowledge, knowledge about the specific communication situation, domain-specific prior knowledge and personal experiences, to create situation models and hence fully understand stories (Meringoff 1980:247; Rai et al. 2011:189; Tibus 2008:12). However, the extent to which the children were able to tap into their knowledge bases seems to have been mediated by the language in which the comprehension questions were asked and answered: While some inferences were not language-dependent, some seemed to have been language-specific, as we obtained the greatest number of 'alternative' answers when the children listened to the Chichewa version of the radio story and answered the questions in Chichewa. Moreover, when the children listened to the story in English and answered the questions in Chichewa they produced significantly more inferences than when they listened to the story in Chichewa and answered the questions in English.

\section{Conclusion}

Inference-making in children has received a considerable amount of attention in the literature, and yet it is still understudied, in particular in bilingual as well as multilingual children and even more so in children who come from backgrounds that are different from mainstream US or European backgrounds that most of the current research is based on. The results of our study indicate that the prerecorded audio recordings seem to have supported inferencemaking more than the corresponding wordless films. The results also indicate that the children from a private school (with English as a medium of instruction) drew more inferences than the children from a public school (where Chichewa is the medium of instruction). Furthermore, the results reveal that while the children were able to use knowledge transfer from a variety of knowledge bases to draw inferences, the inferencing process was impeded when the story content deviated too much from their own experience.

Our data indicate that we need to pay close attention to children's language constellation and socio-economic background as well as their language socialisation, which includes their exposure to alternative narrative styles (for example, oral tradition and folktales). The influence of the latter is very poorly researched and needs further attention. Moreover, we need more research into the 'transferability' of inference-making abilities in one child across his or her different languages. We suspect that language attitudes may interfere with language competence in this domain.

\section{Acknowledgements}

We thank our participants and their parents, as well as Kapita Primary School and Mphungu Primary School for hosting our research. We also thank the audience of our talk presented at the joint annual conference of the Linguistics Society of Southern Africa, the Southern African Applied Linguistics Association and the South African Association for Language Teaching, held from 24 to 26 June 2015 at the North-West University, Potchefstroom, South Africa.

\section{Competing interests}

The authors declare that they have no financial or personal relationships that may have inappropriately influenced them in writing this article.

\section{Authors' contributions}

A.H. was a doctoral student at the University of KwaZuluNatal with H.T. as A.H.'s supervisor, at the time the data were collected. A.H. tested the participants individually in a vacant room at their school. A.H. identified inferences from the participants' answers; H.T. then verified these inferences. A.H. drafted the manuscript, which was rearranged and edited by H.T. A.H. compiled the results and presented them in tables. These results were checked and verified by H.T.

\section{References}

Alptekin, C., 2006, 'Cultural familiarity in inferential and literal comprehension in L2 reading', System 34(4), 494-508. http://dx.doi.org/10.1016/j.system.2006. 05.003

Barnes, M.A., Dennis, M. \& Haefele-Kalvaitis, J., 1996, 'The effects of knowledge availability and knowledge accessibility on coherence and elaborative inferencing in children from six to fifteen years of age', Journal of Experimental Child Psychology 61(3), 216-241. http://dx.doi.org/10.1006/jecp.1996.0015

Bartlett, F.C., 1932, Remembering: A study in experimental and social psychology, Cambridge University Press, Cambridge.

Beagles-Roos, J. \& Gat, I., 1983, 'Specific impact of radio and television on children's story comprehension', Journal of Educational Psychology 75(1), 128-137. http:// dx.doi.org/10.1037/0022-0663.75.1.128

Bowyer-Crane, C. \& Snowling, M.J., 2005, 'Assessing children's inference generation: What do tests of reading comprehension measure?', British Journal of Educational Psychology 75(2), 189-201. http://dx.doi.org/10.1348/000709 Educational

Cain, K. \& Oakhill, J., 1998, 'Comprehension skills and inference-making ability: Issues of causality', in C. Hulme \& R.M. Joshi (eds.), Reading and spelling: Development and disorders, pp. 329-342, Lawrence Erlbaum, Mahwah, NJ.

Cain, K. \& Oakhill, J.V., 1999, 'Inference making ability and its relation to comprehension failure in young children', Reading and Writing 11(5-6), 489-503. http://dx.doi. org/10.1023/A:1008084120205

Calvo, M.G., 2004, 'Relative contribution of vocabulary knowledge and working memory span to elaborative inferences in reading', Learning and Individual Differences 15(1), 53-65. http://dx.doi.org/10.1016/j.lindif.2004.07.002

Carrell, P.L., 1987, 'Content and formal schemata in ESL reading', TESOL Quarterly 21(3), 461-481. http://dx.doi.org/10.2307/3586498

Carrell, P.L. \& Eisterhold, J.C., 1983, 'Schema theory and ESL reading pedagogy', TESOL Quarterly 17(4), 553-573. http://dx.doi.org/10.2307/3586613

Cromley, J.G. \& Azevedo, R., 2007, 'Testing and refining the direct and inferential mediation model of reading comprehension', Journal of Educational Psychology 99(2), 311-325. http://dx.doi.org/10.1037/0022-0663.99.2.311

Cruz de Quirós, A.M., Lara-Alecio, R., Tong, F. \& Irby, B.J., 2012, 'The effect of a structured story reading intervention, story retelling and higher order thinking for English language and literacy acquisition', Journal of Research in Reading 35(1), 87-113.

Erten, I.H. \& Razi, S., 2009, 'The effects of cultural familiarity on reading comprehension', Reading in a Foreign Language 21(1), 60-77.

Fiestas, C.E. \& Peña, E.D., 2004, 'Narrative discourse in bilingual children: Language and task effects', Language Speech and Hearing Services in Schools 35(2), 155-168. http://dx.doi.org/10.1044/0161-1461(2004/016)

Graesser, A.C., Bertus, E.L. \& Magliano, J.P., 1995, 'Inference generation during the comprehension of narrative text', in R.F. Lorch Jr \& E.J. O'Brien (eds.), Sources of coherence in reading, pp. 295-320, Lawrence Erlbaum Associates Inc., Mahwah, NJ. 
Graesser, A.C., León, J.A. \& Otero, J., 2002, 'Introduction to the psychology of science text comprehension', in J. Otero, J.A. León \& A.C. Graesser (eds.), The psychology of science text comprehension, pp. 1-15, Erlbaum, Mahwah, NJ.

Graesser, A.C., Olde, B. \& Klettke, B., 2002, 'How does the mind construct and represent stories?', in M.C. Green, J.J. Strange \& T.C. Brock (eds.), Narrative impact: Social and cognitive foundations, pp. 229-262, Erlbaum, Mahwah, NJ.

Graesser, A.C., Singer, M. \& Trabasso, T., 1994, 'Constructing inferences during narrative text comprehension', Psychological Review 101(3), 371-395. http://dx. doi.org/10.1037/0033-295X.101.3.371

Hara, A., 2015, 'Text comprehension in multilingual children: Mental representation and narrative text structure', PhD thesis, Department of Linguistics, University of KwaZulu-Natal.

Hecht, S.A., Burgess, S.R., Torgesen, J.K., Wagner, R.K. \& Rashotte, C.A., 2000 'Explaining social class differences in growth of reading skills from beginnin kindergarten through fourth-grade: The role of phonological awareness, rate of access, and print knowledge', Reading and Writing 12(1-2), 99-128. http://dx.doi. org/10.1023/A:1008033824385

Horiba, Y., 1996, 'Comprehension processes in L2 reading: Language competence, textual coherence, and inferences', Studies in Second Language Acquisition 18(4), 433-473. http://dx.doi.org/10.1017/\$0272263100015370

Jalilifar, A.R. \& Assi, R., 2008, 'The role of cultural nativization in comprehension of short stories in EFL reading contexts', The International Journal of Language Society and Cultural Issue 26, 62-79.

Johnson, P., 1981, 'Effects on reading comprehension of language complexity and cultural background of a text', TESOL Quarterly 15(2), 169-181. http://dx.doi. org/10.2307/3586408

Johnson-Laird, P.N., 1983, Mental models: Towards a cognitive science of language, inference, and consciousness, Cambridge University Press, Cambridge.

Keenan, J.M., Baillet, S.D. \& Brown, P., 1984, 'The effects of causal cohesion on comprehension and memory', Journal of Verbal Learning and Verbal Behavio 23(2), 115-126. http://dx.doi.org/10.1016/S0022-5371(84)90082-3

Kembo, J.A., 2001, 'Testing of inferencing behaviour in a second language' International Journal of Bilingual Education and Bilingualism 4(2), 77-96. http:// dx.doi.org/10.1080/13670050108667720

Kintsch, W., 1988, 'The role of knowledge in discourse comprehension: A constructionintegration model', Psychological Review, 95(2), 163-182. http://dx.doi. org/10.1037/0033-295X.95.2.163

Kintsch, W., 1998, Comprehension: A paradigm for cognition, Cambridge University Press, Cambridge.

Kintsch, W., 2004, 'The construction-integration model of text comprehension and its implications for instruction', Theoretical Models and Processes of Reading 5 1270-1328. http://dx.doi.org/10.1598/0872075028.46

Kintsch, W. \& Green, E., 1978, 'The role of culture specific schemata in the comprehension and recall of stories', Discourse Processes 1, 1-13. http://dx.doi. org/10.1080/01638537809544425

Kintsch, W. \& van Dijk, T.A., 1978, 'Toward a model of text comprehension and production', Psychological Review 85(5), 363-394. http://dx.doi. org/10.1037/0033-295X.85.5.363

Kispal, A., 2008, Effective teaching of inference skills for reading: Literature review, viewed 20 December 2015, from http://dera.ioe.ac.uk/7918/1/DCSF-RR031.pdf
Li, C.H. \& Lai, S.F., 2012, 'The functions of cultural schemata in the Chinese reading comprehension and reading time of college students in Taiwan', Journal of International Education Research (JIER) 8(2), 105-112. http://dx.doi. org/10.19030/jier.v8i2.6830

Linebarger, D.L. \& Piotrowski, J.T., 2009, 'TV as storyteller: How exposure to television narratives impacts at-risk preschoolers' story knowledge and narrative skills', British Journal of Developmental Psychology 27(1), 47-69. http://dx.doi. org/10.1348/026151008X400445

Long, D.L., Seely, M.R., Oppy, B.J. \& Golding, J.M., 1996, The role of inferential processing in reading ability, Lawrence Erlbaum Associates, Hillsdale, NJ.

McKoon, G. \& Ratcliff, R., 1992, 'Inference during reading', Psychological Review 99(3), 440-466. http://dx.doi.org/10.1037/0033-295X.99.3.440

Meringoff, L.K., 1980, 'Influence of the medium on children's story apprehension', Journal of Educational Psychology 72 (2), 240-249. http://dx.doi. org/10.1037/0022-0663.72.2.240

Patterson, J.L., 2002, 'Relationships of expressive vocabulary to frequency of reading and television experience among bilingual toddlers', Applied Psycholinguistics 23(4), 493-508. http://dx.doi.org/10.1017/S0142716402004010

Pressley, M. \& Afflerbach, P., 1995, Verbal protocols of reading: The nature of constructively responsive reading, Lawrence Erlbaum Associates, Hillsdale, NJ.

Pritchard, R., 1990, 'The effects of cultural schemata on reading processing strategies', Reading Research Quarterly 25(4), 273-295. http://dx.doi.org/10.2307/747692

Rai, M.K., Loschky, L.C., Harris, R.J., Peck, N.R. \& Cook, L.G., 2011, 'Effects of stress and working memory capacity on foreign language readers' inferential processing during comprehension', Language Learning 61(1), 187-218. http://dx.doi. org/10.1111/j.1467-9922.2010.00592.x

Salomon, G., 1984, "Television is "easy" and print is "tough": The differentia investment of mental effort in learning as a function of perceptions and attributions', Journal of Educational Psychology 74, 647-658. http://dx.doi. org/10.1037/0022-0663.76.4.647

Sasaki, M., 2000, 'Effects of cultural schemata on students' test-taking processes for cloze tests: A multiple data source approach', Language Testing 17(1), 85-114.

Scheele, A.F., Leseman, P.P. \& Mayo, A.Y., 2010, 'The home language environment of monolingual and bilingual children and their language proficiency', Applied Psycholinguistics 31(1), 117-140. http://dx.doi.org/10.1017/S0142716409990191

Severing, R. \& Verhoeven, L., 2001, 'Bilingual narrative development in Papiamento and Dutch', in L. Verhoeven \& S. Strömqvist Narrative development in a multilingual context, pp. 255-276, John Benjamins, Amsterdam.

Slatalla, M., 2001, 'Chores, anyone?', Time 157(8), 75.

Tappe, H. \& Hara, A., 2013, 'Language specific narrative text structure elements in multilingual children', Stellenbosch Papers in Linguistics Plus 42, 297-331. http:// dx.doi.org/10.5842/42-0-160

Tibus, M., 2008, 'Do films make you think? Inference processes in expository film comprehension', Doctoral dissertation, University of Tübingen, viewed 16 December 2015, from http://publikationen.uni-tuebingen.de.

Van Dijk, T.A. \& Kintsch, W., 1983, Strategies of discourse comprehension, Academic Press, New York.

Walter, C., 2004, 'Transfer of reading comprehension skills to L2 is linked to mental representations of text and to L2 working memory', Applied Linguistics 25(3), 315-339. http://dx.doi.org/10.1093/applin/25.3.315 